\title{
Pathways regulating the expression of the immunomodulatory protein glycodelin in non-small cell lung cancer
}

\author{
REBECCA WEBER $^{1,2}$, MICHAEL MEISTER ${ }^{1,2}$, THOMAS MULEY ${ }^{1,2}$, MICHAEL THOMAS $^{2,3}$, \\ HOLGER SÜLTMANN ${ }^{2,4}$, ARNE WARTH ${ }^{2,5,8}$, HAUKE WINTER ${ }^{2,6}$, \\ FELIX J.F. HERTH ${ }^{2,7}$ and MARC A. SCHNEIDER ${ }^{1,2}$ \\ ${ }^{1}$ Translational Research Unit, Thoraxklinik at Heidelberg University Hospital, 69126 Heidelberg; \\ ${ }^{2}$ Translational Lung Research Center Heidelberg, member of the German Centre for Lung Research (DZL-TLRC), \\ 69120 Heidelberg; ${ }^{3}$ Department of Thoracic Oncology, Thoraxklinik at Heidelberg University Hospital, \\ 69126 Heidelberg; ${ }^{4}$ Division of Cancer Genome Research Group, German Cancer Research Centre (DKFZ) and \\ German Cancer Consortium (DKTK); ${ }^{5}$ Institute of Pathology, University of Heidelberg, 69120 Heidelberg; \\ Departments of ${ }^{6}$ Surgery and ${ }^{7}$ Pneumology, Thoraxklinik at Heidelberg University Hospital, 69126 Heidelberg, Germany
}

Received September 29, 2018; Accepted November 9, 2018

DOI: $10.3892 /$ ijo.2018.4654

\begin{abstract}
Glycodelin [gene name, progesterone associated endometrial protein $(P A E P)]$ was initially described as an immune system modulator in reproduction. Today, it is also known to be expressed in several types of cancer, including non-small cell lung cancer (NSCLC). In this cancer type, the feasibility of its usage as a follow-up biomarker and its potential role as an immune system modulator were described. It is assumed that NSCLC tumours secrete glycodelin to overcome immune surveillance. Therefore, targeting glycodelin might be a future approach with which to weaken the immune system defence of NSCLC tumours. In this context, it is important to understand the regulatory pathways of $P A E P /$ glycodelin expression, as these are mostly unknown so far. In this study, we analysed the influence of several inducers and of their downstream pathways on $P A E P /$ glycodelin expression in a human lung adenocarcinoma carcinoma (ADC; H1975) and a human lung squamous cell carcinoma (SQCC) cell line (2106T). PAEP/glycodelin expression was notably stimulated by the canonical transforming growth factor (TGF) $\beta$ pathway in SQCC cells and the PKC signalling cascade in both cell
\end{abstract}

Correspondence to: Dr Marc A. Schneider, Translational Research Unit, Thoraxklinik at Heidelberg University Hospital, Roentgenstrasse 1, 69126 Heidelberg, Germany

E-mail: marc.schneider@med.uni-heidelberg.de

Present address: ${ }^{8} \mathrm{UEGP}$ MVZ Institute of Pathology, Cytopathology and Molecular Pathology, 35578 Wetzlar, Germany

Key words: non-small cell lung cancer, glycodelin, progesterone associated endometrial protein, immunomodulatory, signalling pathways, transforming growth factor- $\beta$, protein kinase $\mathrm{C}$, protein kinase B lines. The PI3K/AKT pathway inhibited $P A E P /$ glycodelin expression in the ADC cells and an antagonizing role towards the other investigated signalling cascades is suggested herein. Furthermore, the mitogen-activated protein kinase kinase (MEK)/extracellular-signal regulated kinases (ERK) pathway was, to a lesser extent, found to be associated with increased $P A E P /$ glycodelin amounts. The phosphoinositide 3-kinase $(\mathrm{PI} 3 \mathrm{~K}) /$ protein kinase B (AKT), MEK/ERK pathway and TGF- $\beta$ are targets of NSCLC drugs that are already approved or are currently under investigation. On the whole, the findings of this study provide evidence that inhibiting these targets affects the expression of glycodelin and its immunosuppressive effect in NSCLC tumours. Moreover, understanding the regulation of glycodelin expression may lead to the development of novel therapeutic approaches with which to weaken the immune system defence of NSCLC tumours in the future.

\section{Introduction}

With approximately 1.8 million new diagnosed cases in 2012, lung cancer is one of the most common types of cancer, accounting for the most frequent cancer-related deaths (1.6 million) worldwide (1). Approximately $80-85 \%$ of these lung cancer patients suffer from the subtype, non-small cell lung cancer (NSCLC). The reasons for the high mortality rate of this cancer type are not only the late detection of the disease, but also due to the limited treatment options. Mutations within the epidermal growth factor receptor (EGFR) occur frequently in NSCLC. Often this mutation leads to a constitutive activation of the receptor and increases downstream signalling cascades, such as the mitogen-activated protein kinase kinase (MEK)/extracellular-signal regulated kinases (ERK), phosphoinositide 3-kinase (PI3K)/protein kinase B (AKT) and signal transducer and activator (STAT) pathway. Consequently, proliferation and angiogenesis, as well as metastasis are increased and apoptosis is decreased (2), which promotes tumour growth. 
Glycodelin [gene name, progesterone associated endometrial protein $(P A E P)]$ is a protein initially described in reproduction. The four isoforms glycodelin A, S $(3,4)$, $\mathrm{F}$ and $\mathrm{C}(5)$, differ in their glycosylation patterns. Each of them has different biological functions, such as influencing the capacitation, acrosome reaction, sperm-oocyte binding and immune system suppression during the establishment of pregnancy $(6,7)$. In the female reproduction system, glycodelin synthesis can be increased by progesterone (8), human chorionic gonadotropin (hCG) $(9,10)$ and relaxin $(11)$.

Additionally, $P A E P /$ glycodelin is known to be expressed not only in female-specific tumours, such as breast (12), endometrial (13), ovarian (14) and cervical cancer (15), but also in biphasic synovia sarcomas (16), melanoma (17), malignant pleural mesothelioma (18) and lung cancer $(19,20)$. It has been shown that $P A E P /$ glycodelin expression is associated with both a better and worse prognosis in these different cancer types (20-23). However, in general, glycodelin seems to promote tumour malignancy by influencing proliferation, differentiation, invasion, angiogenesis and the immune system (24). In a previous study, we identified glycodelin as a potent follow-up biomarker for NSCLC, since increased levels of glycodelin were associated with recurrence and metastatic disease in patients' sera (20). Furthermore, an altered cell structure, a reduced migration and the upregulation of immune system-regulating ligands was observed in NSCLC cell lines in which PAEP expression was silenced (20). These results suggest that NSCLC tumours secrete glycodelin to overcome immune surveillance. Therefore, glycodelin may be a potential target to weaken immune system defence of NSCLC tumours. Pathways regulating $P A E P /$ glycodelin expression in cancer might provide some insight in this respect. However, they are, particularly in lung cancer, mostly unknown. A few inducers and components of pathways, which are commonly altered in cancer, have already been described to influence glycodelin expression. In a myelogenous leukaemia cell line, $P A E P /$ glycodelin expression was shown to be stimulated by phorbol 12-myristate 13 acetate (PMA) (25). Lysophosphatidic acid (LPA) has also been shown to elevate $P A E P /$ glycodelin expression in cervical, endometrial, ovarian cancer and myelogenous leukaemia cell lines (26). Since PMA and LPA are known as protein kinase C (PKC) activators $(27,28)$, it might be of interest to determine whether $P A E P / g l y c o d e l i n$ expression is influenced by this kinase. Furthermore, the inhibition of MEK1/2 and protein kinase A has been described to attenuate phytoestrogen-induced glycodelin expression (29). Other previous studies have postulated that the activation of PAEP expression is associated with the transcription factors GATA-binding protein 3 (GATA3), the microphthalmia-associated transcriptions factor (MITF) and the specific protein1 (Sp1) (30-32). Only the Krüppel-like transcription factor11 (KLF11) has been assumed to suppress glycodelin expression (33).

Based on these facts, the aim of this study was to gain insight into the so far unknown underlying mechanisms regulating $P A E P / g l y c o d e l i n$ expression in NSCLC. Therefore, we analysed the effects of various pathway inducers and their downstream signalling cascades, all of which are known as major regulators in cancer, on $P A E P /$ glycodelin expression in two NSCLC cell lines. Moreover, the in vitro data were validated in NSCLC patient tissue.

\section{Materials and methods}

Tissue sample collection. Tissue samples from patients with NSCLC were provided by the Lung Biobank Heidelberg, a member of the accredited Tissue Bank of the National Centre for Tumour Diseases (NCT) Heidelberg, the BioMaterialBank Heidelberg and the Biobank Platform of the German Centre for Lung Research (DZL). Written informed consent was obtained from all participants and/or their legal guardian/s before the use of the tissue for research purpose. The study was approved by the local Ethics Committee of the University of Heidelberg (no. 270/2001) and all experiments were performed in accordance with relevant guidelines and regulations. A total of 179 patients with NSCLC, who underwent surgical resection at the Thoraxklinik Heidelberg, were included. Tumour tissue, as well as the corresponding healthy lung parenchyma, with a distance of $>5 \mathrm{~cm}$ from the tumour, was used. A pathologist made the diagnosis in compliance with the World Health Organization (WHO) classification for lung cancer from 2004 (34). Tumours were staged according to the 7th edition of the Union for International Cancer Control's (UICC) tumour, node and metastasis (35). Following surgical resection, tissues were snap-frozen in liquid nitrogen within $30 \mathrm{~min}$ and stored at $-80^{\circ} \mathrm{C}$ until subsequent processing.

Cell culture. The H1975 lung adenocarcinoma (ADC) cell line was purchased from American Type Culture Collection (CRL-5908; ATCC, Manassas, VA, USA) and authenticated by DNA profiling using 8 different and highly polymorphic short tandem repeat (STR) (Leibniz-Institut DSMZ, Braunschweig, Germany). The 2106T cells were generated from a human lung squamous cell carcinoma (SQCC) and characterised as previously described (36). Both cell lines were maintained in DMEM/Ham's F-12 (Thermo Fisher Scientific, Carlsbad, CA, USA) supplemented with $1 \%$ GlutaMAXTM 100x (Thermo Fisher Scientific) and $10 \%$ foetal calf serum (FCS; Thermo Fisher Scientific).

siRNA-mediated gene depletion. The H1975 and 2106T cells were seeded into a 12 -well plate at an initial density of $4 \times 10^{4}$ cells per well. The following day, the cells were transfected with small interfering ribonucleic acids (siRNAs; Qiagen, Hilden, Germany) targeting JUNB (JUNB_3: acagactcgattcatattgaa; JUNB_4: aaacacgcacttagtctctaa; JUNB_5: cccgacgaccaccatcagcta), NF-кB1 (NFkB1_7: tacctggtgcctctagtgaaa; NFkB1_8: tcagttggtcacaaatggaaa;NFKB1_10: gacgccatctatgacagtaaa) and STAT3 (STAT3_3: ctggtcttaactctgattgta; STAT3_4: cacctttgagaccgaggtgta; STAT3_7: cagcctctctgcagaattcaa; STAT3_8: caggctggtaatttatataat) using Lipofectamine ${ }^{\mathrm{TM}}$ RNAiMax (Thermo Fisher Scientific) according to the manufacturer's instructions. Therefore, a pool of 3 to 4 different siRNAs, as well as the particular single siRNAs were used. AllStars negative control siRNA (Qiagen) served as a non-silencing control. The siRNAs were applied at a final concentration of $10 \mathrm{nM}$. At $72 \mathrm{~h}$ following transfection, the cells were processed for total RNA isolation or western blot analysis.

Applying signalling pathway modulators. Both cell lines were seeded into a 12 -well plate at $1.6 \times 10^{5}$ cells per well. The 
following day, the cells were serum-starved for approximately $16 \mathrm{~h}$. For determining $P A E P /$ glycodelin expression, the cells were subsequently treated with distinct pathway inducers or modulators for $24 \mathrm{~h}$, solely the PKC activator Bryostatin (Santa Cruz Biotechnology, Heidelberg, Germany) was used for $1 \mathrm{~h}$. To detect phosphorylated pathway components or transcription factors, the cells were treated only for $30 \mathrm{~min}$ to $1 \mathrm{~h}$. Following the different treatments, the cells were prepared for total ribonucleic acid (RNA) isolation or western blot analysis. The following signalling pathway inducers and modulators were used: LPA (Santa Cruz Biotechnology), PMA (Cayman Chemical, Ann Arbor, MI, USA), epidermal growth factor (EGF; Biomol, Hamburg, Germany), heparin-binding (HB)-EGF (Biomol), TGF- $\beta 1,-2,-3$ (WuXi Biosciences, San Diego, CA, USA), Bryostatin1 (Selleckchem, Houston, TX, USA), GF109203X (StressMarq Biosciences, Victoria, BC, Canada), MK-2206 (Selleckchem) as well as RO5126766 (Selleckchem).

Cell lysis and western blot analysis. The cells were lysed with $2 \mathrm{X}$ sodium dodecyl sulfate (SDS) sample buffer (0.13 M Tris HCL pH 6.8, 10\% glycerol, 4\% SDS, $1.4 \mathrm{mM} \beta$-mercaptoethanol and $1 \%$ pyronine) and boiled for $5 \mathrm{~min}$ at $95^{\circ} \mathrm{C}$. After separating the samples on a SDS-polyacrylamide gel (10 or $15 \%$, self-made), they were transferred to a nitrocellulose membrane. According to the manufacturer's instructions, the membrane was incubated wih the primary antibodies overnight at $4^{\circ} \mathrm{C}$ and subsequent incubation with the secondary antibody was performed for $1 \mathrm{~h}$ at room temperature. The following primary antibodies were used: $\beta$-actin $(1: 10,000, \mathrm{AC}-15$; anti-mouse; cat. no. A5441; Sigma-Aldrich, Steinheim, Germany), glycodelin 1:300 (N20; anti-goat; cat. no. sc-12289; Santa Cruz Biotechnology), Smad2/3 1:1,500 (anti-mouse; cat. no. 610843; BD Biosciences, Franklin Lakes, NJ, USA), AKT (pan; 1:2,000; C67E7; anti-rabbit; cat. no. 4691), JUNB (1:2,500; C37F9; anti-rabbit; cat. no. 3753), NF- $\mathrm{B}$ p105/p50 (1:2,000; anti-rabbit; cat. no. 3035), p44/42 MAPK (Erk1/2; 137F5; 1:2,000; anti-rabbit; cat. no. 4695), phospho-AKT (Thr308; 1:1,000; D25E6; anti-rabbit; cat. no. 13038) XP ${ }^{\circledR}$, phospho-JUNB (Thr102/Thr104; 1:2,500; D3C6; anti-rabbit; cat. no. 8053), phospho-NF-кB p105 (Ser933; 1:1,000; 18E6; anti-rabbit; cat. no. 4806), phospho-p44/42 MAPK (Erk1/2; Thr202/Tyr204; 1:2,000; anti-rabbit; cat. no. 9101), phospho-PKC substrate motif [(R/KXpSX(R/K)] MultiMabTM (1:750; anti-rabbit; cat. no. 6967), phospho-Smad2 (Ser465/467; 1:1,000; 138D4; anti-rabbit; cat. no. 3108), phospho-STAT3 (Ser727; 1:1,000; 6E4; anti-mouse; cat. no. 9136) and STAT3 (1:1,500; 124H6; anti-mouse; cat. no. 9139) (all from Cell Signalling Technology ${ }^{\circledR}$, Danvers, MA, USA). Horseradish peroxidase (HRP)-coupled secondary antibodies (peroxidase-linked goat IgG (cat. no. A5420); peroxidase-linked mouse IgG (cat. no. A4416); peroxidase-linked rabbit IgG (cat. no. A6154); all 1:5,000) were purchased from Sigma-Aldrich. The brightness and contrast of the western blot images were adjusted using the software adobe photoshop elements13 (Adobe Systems, San Jose, CA, USA).

Total RNA isolation and cDNA synthesis. For RNA isolation from patient tumour tissue, a tumour content of $\geq 50 \%$ was the minimum prerequisite. A total of 10-15 tumour cryosections $(10-15 \mu \mathrm{M})$ from each patient were sliced and the first, as well as the last section of a series were stained with haematoxylin and eosin (H\&E). A lung pathologist determined the proportion of viable tumour cells, stromal cells, healthy lung cells and necrotic areas. Total RNA was isolated from patient tissue using an AllPrep DNA/RNA/miRNA Universal kit (Qiagen) according to the manufacturer's instructoins. An RNeasy Mini kit (Qiagen) was applied to isolate RNA from the cell lines. Afterwards, the quality of total RNA was assessed by utilizing an Agilent 2100 Bioanalyser and an Agilent RNA 6000 Nano kit (Agilent Technologies, Boeblingen, Germany). With the Transcriptor First Strand cDNA Synthesis kit (Roche, Basel, Switzerland) the total RNA was transcribed to complementary desoxyribonucleic acid (cDNA) and used for quantitative polymerase chain reaction (qPCR). A complete description of the procedure is provided elsewhere (20).

$q P C R$. A total of $5 \mathrm{ng}$ of the cDNA was utilized for $\mathrm{qPCR}$ with the LightCycler480 ${ }^{\circledR}$ (Roche) in a 384-well plate format according to the Minimum Information for Publication of qPCR Experiments (MIQE)-guidelines (37). In the context of a Universal ProbeLibrary (UPL) assay (Roche), gene-specific primers (TIB Molbiol, Berlin, Germany) were combined with the primaQuant 2X qPCR Probe-MasterMix (Steinbrenner Laborsysteme, Wiesenbach, Germany). Threshold cycle $(\mathrm{Ct})$-values were evaluated with the LightCycler $480^{\circledR}$ software release 1.5 and the 2 nd derivative maximum method (Roche). The complete procedure is described elsewhere (20). The following primers and UPLswere used:ESD forward(UPL\#50), tcagtctgcttcagaacatgg and ESD reverse (UPL \#50), cctttaatattgcagccacga; JUNB forward (UPL \#32), caaggtgaagacgctcaagg and JUNB reverse (UPL \#32), tcatgaccttctgtttgagctg; NF- $\kappa$ B forward (UPL \#49), cctggaaccacgectcta and NF- $\kappa B$ reverse (UPL \#49), ggctcatatggtttcccattta; PAEP forward (UPL \#77), cctgtttctctgcctacagga and PAEP reverse (UPL \#77), cgtcctccaccaggactct; RPS forward (UPL \#46), cttccacaggaggcctacac and RPS reverse (UPL \#46), cgcaaaatatgctggaacttt; and STAT3 forward (UPL \#17), gagcagagatgtgggaatgg and STAT3 (UPL \#17) reverse, cggtctcaaaggtgatcagg.

Microarray gene expression profiling. Isolated RNA from the cells and patient tissue was further processed with the GeneChip $^{\text {TM }}$ 3' IVT PLUS Reagent kit (Thermo Fisher Scientific) and the GeneChip ${ }^{\mathrm{TM}}$ Human Genome U133 Plus 2.0 Array (Thermo Fisher Scientific) according to the manufacturer's instructions. For gene expression profiling of the patient tissues, we selected samples with the highest or lowest PAEP expression (40 ADCs and 30 SQCCs), which was determined by qPCR analyses in our previous study (20). The raw data were normalized using the software Expression Console $^{\mathrm{TM}}$ (Thermo Fisher Scientific) [Algorithm: robust multi-array average (RMA)] and analysed by Transcriptome

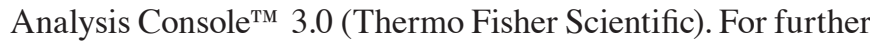
evaluation with the software Ingenuity pathway analysis (IPA; IPA-42012434; Qiagen) (upstream regulator analysis), only genes with an expression fold-change $<-1.5$ or $>1.5$ were considered. A detailed description of the IPA analysis is available on the manufacturer's homepage (https://www. qiagenbioinformatics.com/products/features/). The microarray 


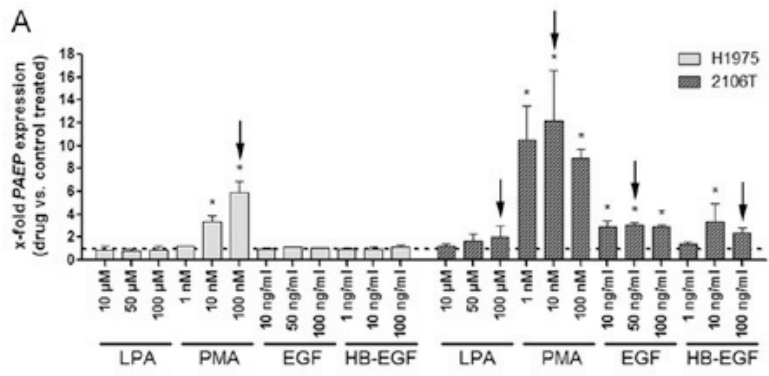

\begin{tabular}{|c|c|c|c|c|c|}
\hline C & H1975 & $2106 \mathrm{~T}$ & & & \\
\hline Upstream regulators & PMA & LPA & PMA & EGF & HB-EGF \\
\hline TNF & 10,15 & 4,99 & 6,04 & 3,67 & 2.25 \\
\hline IL.1B & 8.05 & 4.62 & 5.10 & 4.25 & 2.23 \\
\hline NUPR1 & 9,99 & 1,33 & 5,93 & 2,83 & 2,11 \\
\hline Phorbol myristate acetate & 6,24 & 3,82 & 6,02 & 3,71 & 1,74 \\
\hline IL 1 A & 6.55 & 4,10 & 3,76 & 3,78 & 1,72 \\
\hline F2 & 3,21 & 4,78 & 5,27 & 4,11 & 2,26 \\
\hline TGF- $\beta 1$ & 1,98 & 4,81 & 5.20 & 4,58 & 2,55 \\
\hline TREM1 & 3.25 & 3,01 & 5,76 & 3,06 & 3,84 \\
\hline NF-kB (complex) & 5,67 & 3,90 & 4,39 & 3,51 & 0,76 \\
\hline RELA & 4,72 & 3,52 & 4,40 & 2,68 & 2,32 \\
\hline PD98059 & $\begin{array}{r}-3,58 \\
\end{array}$ & $-2,75$ & $-5,28$ & $-4,33$ & $-1,55$ \\
\hline PRKCD & 4,59 & 3,31 & 4,40 & 3,08 & 2,06 \\
\hline iL.1 & 5,11 & 3,71 & 3,47 & 2,62 & 1,60 \\
\hline U0126 & $-3,67$ & $-2,33$ & $-4,00$ & $-3,91$ & $-2,11$ \\
\hline SMARCA4 & 4,47 & 3,15 & 3,23 & 2.83 & 2,31 \\
\hline RAF1 & 2,57 & 3,32 & 4,57 & 3,14 & 2,20 \\
\hline ERK1/2 & 2,85 & 3,14 & 4,27 & 3,22 & 1,91 \\
\hline PPRC1 & 4,52 & 2,40 & 3,60 & 2,40 & 2,20 \\
\hline poly ft.rC-RNA & 6,88 & 2,23 & 0,87 & 3,64 & 1,42 \\
\hline IFNG & 7,45 & 2,09 & $-0,50$ & 3,92 & 0,88 \\
\hline TNF (lamily) & 3.22 & 3,93 & 2,74 & 2,69 & 1,95 \\
\hline TLR4 & 4,91 & 2,96 & 2,28 & 2,80 & 1,44 \\
\hline PDGF BB & 3,84 & 2,35 & 3,98 & 2,78 & 1,42 \\
\hline IL 18 & 4,11 & 3,18 & 2,68 & 2,47 & 1,93 \\
\hline EGFR & 1,27 & 2,37 & 3,75 & 4,74 & 2,15 \\
\hline ILIRN & -6.23 & $-2,52$ & 0.04 & $-3,09$ & $-2,24$ \\
\hline Mek & 1,09 & 3,34 & 4,54 & 2,49 & 2,42 \\
\hline Lysophosphatidic acid & 1,98 & 3,94 & 1,92 & 3,47 & 2,55 \\
\hline MYDB8 & 4.90 & 2,78 & 2.81 & 2,47 & 0,86 \\
\hline $\operatorname{Tir}$ & 4,17 & 2,59 & 2,86 & 2,61 & 1,59 \\
\hline IRF7 & 5,49 & $\begin{array}{l}-1,01 \\
-1,01\end{array}$ & $-4,81$ & 2,41 & NA \\
\hline 5-0-mycoly-beta-araf-(1->2)-5. & & & & & \\
\hline $\begin{array}{l}\text { O-mycolyl-alpha-araf-(1->1')- } \\
\text { glycerol }\end{array}$ & 4,94 & 2,49 & 2,87 & 2,52 & 0,90 \\
\hline TLR7 & 5,48 & 2,56 & 1,05 & 2,69 & 1,89 \\
\hline IL17A & 4,18 & 2,01 & 3.64 & 2,90 & 0.95 \\
\hline JUN & 2,66 & 2,83 & 3,46 & 2,64 & 2,05 \\
\hline FOXL2 & 2,62 & 2,23 & 3,76 & 3,14 & 1,85 \\
\hline reactive oxygen species & 2,51 & 2,47 & 3,06 & 3,09 & 2,39 \\
\hline & 1,89 & 2,26 & 4.25 & 3,46 & 1,52 \\
\hline NF-kB1 & 2,97 & 2,09 & 2,56 & 3,04 & 2,71 \\
\hline A 1 & 4.04 & 199 & 293 & 272 & 1.67 \\
\hline
\end{tabular}
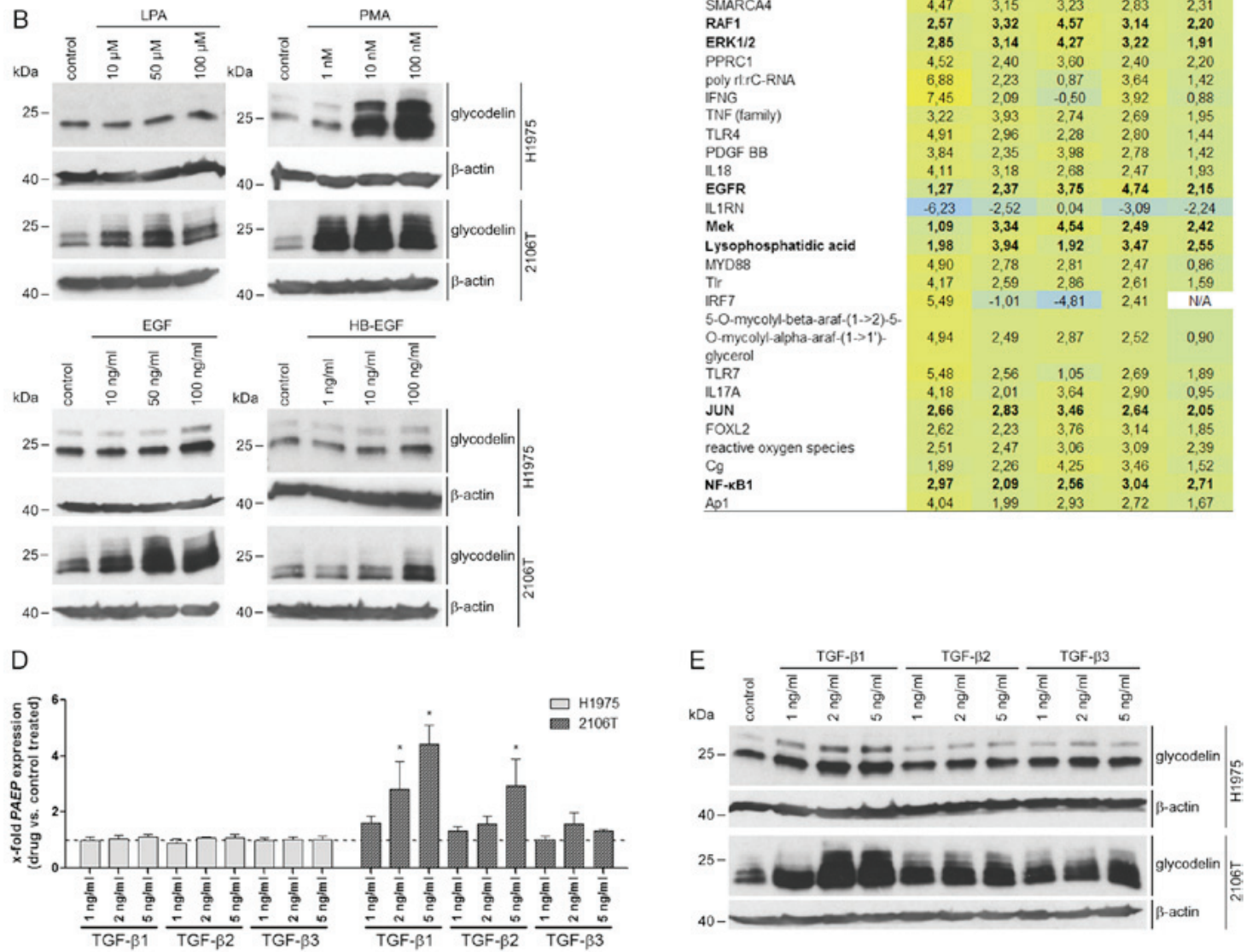

Figure 1.PAEP/glycodelin expression is stimulated by the pathway inducers, LPA, PMA, EGF, HB-EGF and TGF- $\beta$ in NSCLC cells. (A, B, D and E) Overnight serum-starved H1975 and 2106T cells were treated with the indicated pathway inducers for $24 \mathrm{~h}$. (A and D) PAEP expression following pathway induction compared to the controls is shown from 3 independent experiments. Dotted line at 1 represents the expression in the control-treated cells (mean of the $\mathrm{C}_{\mathrm{t}}$-values and mean SD are shown). Black arrows mark the samples used in (C). Statistical significance was defined as " $\mathrm{P}<0.05$ (one-way ANOVA and Dunnett's test; referring to control-treated cells). (B and E) Glycodelin expression in cells treated with pathway inducers was detected by western blot analysis. $\beta$-actin served as a loading control (cropped blots are shown). (C) Cells were treated only with pathway inducers that stimulated PAEP expression. Corresponding microarray gene expression profiling data were evaluated with an upstream regulator analysis by the software Ingenuity Pathway Analysis (IPA). Shown are the activation $\mathrm{z}$-scores (significant for $>2$ or $<-2$ ). Upstream regulators are marked in bold, if they were examined in further experiments. PAEP, progesterone associated endometrial protein; NSCLC, non-small cell lung cancer; LPA, lysophosphatidic acid; PMA, phorbol 12-myristate 13 acetate; EGF, epidermal growth factor; HB-EGF, heparin-binding epidermal growth factor; TGF- $\beta$, transforming growth factor- $\beta$.

data, which were part of this study, are available as described below.

Statistical analysis. Expression differences investigated by qPCR between the control and pathway inducer/modulator-treated cells or control siRNA- and siRNA-transfected cells were evaluated utilizing the software GraphPad Prism 5 (GraphPad Software, La Jolla, CA, USA). Statistical significance was calculated using one-way ANOVA with Dunnett's test for multiple comparisons or an unpaired t-test for single comparisons. A P-value $<0.05$ was considered to indicate a statistically significant difference, since this study had an explorative character.

\section{Results}

The pathway inducers LPA, PMA, EGF, HB-EGF and TGF- $\beta$ increase the expression of $P A E P / g l y c o d e l i n$. In a recent study of ours, we screened different lung ADC and lung SQCC cell lines regarding their glycodelin expression (20). Among these histological subtypes, H1975 [containing the EGFR mutations (T790M and L858R), as well as the PIK3CA mutation (G118D)] and 2106T were the only cell lines that secreted glycodelin. In NSCLC, various mutations activate different pathways, such as the MEK/ERK, PI3K/AKT and/or STAT signalling cascades. This is also the case in H1975 cells due to their EGFR and PIK3CA mutations. By using the H1975 and 2106T cells in 


\section{A}
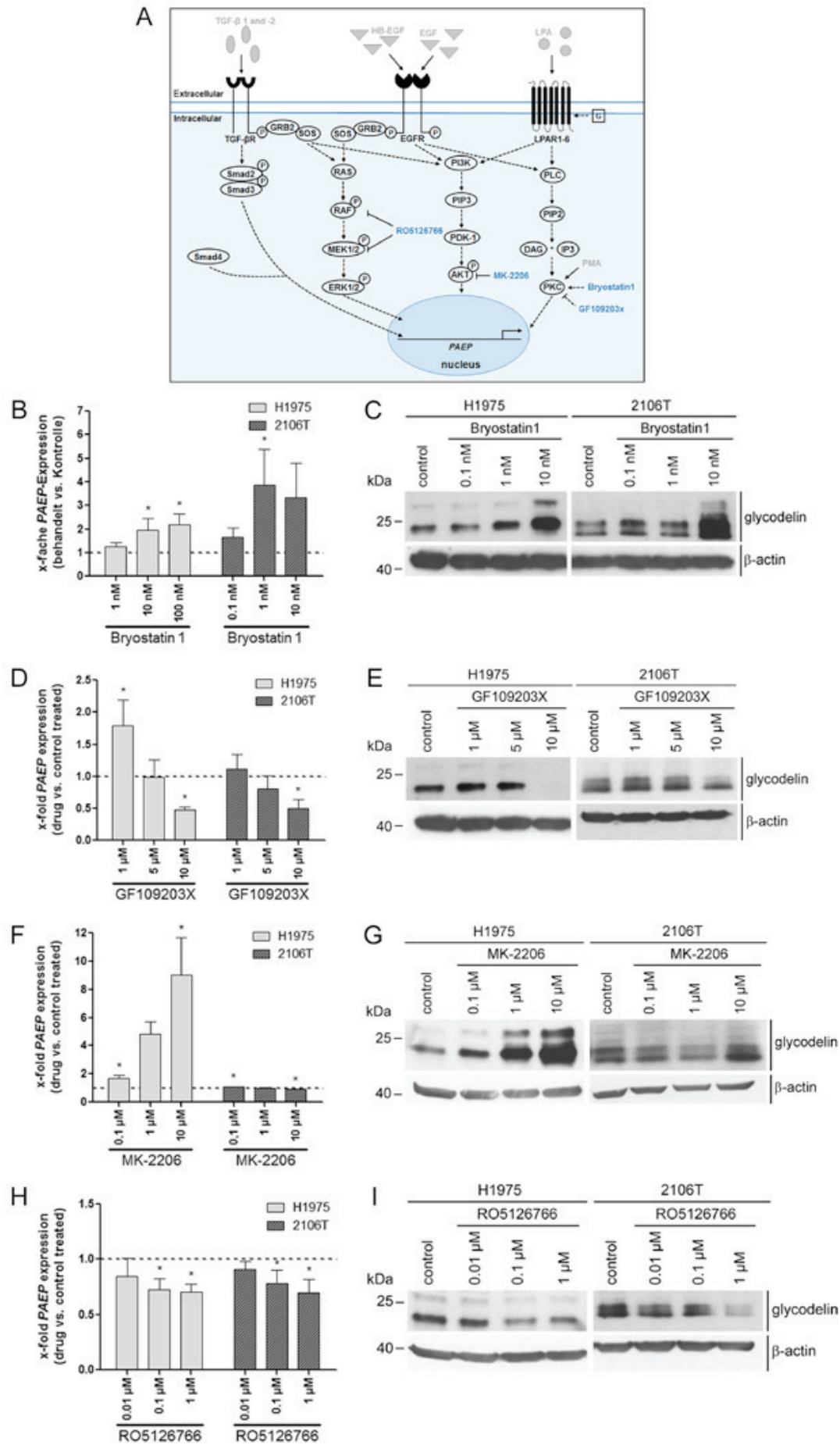

Figure 2. Downstream signalling pathways including PKC, AKT and RAF/MEK affected PAEP/glycodelin levels in NSCLC cells. (A) Overview of previously investigated pathway inducers (grey with drawn down arrows) and components of signalling pathways that were analysed in the next experiments (blue). Dotted arrows depict assumed or literature data based relationships between signalling pathway regulators. (B-I) Two NSCLC cell lines were serum-starved overnight. The cells were then cultivated with an activator of PKC (Bryostatin) for $1 \mathrm{~h}$, as well as with inhibitors of PKC (GF109203X), AKT (MK-2206) and RAF/MEK (RO5126766) for 24 h. (B, D, F and H) qPCR visualizing PAEP expression was performed from 3 independent experiments. Dotted line at 1 represents the expression in control-treated cells (mean of the $\mathrm{C}_{\mathrm{t}}$-values and mean SD are shown). Statistical significance was defined as ${ }^{*} \mathrm{P}<0.05$ (one-way ANOVA and Dunnett's test; referring to control-treated cells). (C, E, G and I) Western blot analysis detected the glycodelin levels. $\beta$-actin was used as a loading control (cropped blots are shown). PAEP, progesterone associated endometrial protein; NSCLC, non-small cell lung cancer; PKC, protein kinase C.

the following experiments, we covered a rather representative range of mutation associated activated, as well as unaffected pathways in NSCLC.

First, the effects of several pathway inducers on $P A E P /$ glycodelinexpressionwereexaminedbyqPCRandwestern blot analysis in the H1975 and 2106T cells (Fig. 1A and B).
Additionally, to the already described $P A E P /$ glycodelin expression stimulators LPA and PMA $(25,26)$, we also selected EGF, as well as HB-EGF. Both are ligands of the EGFR, which plays a crucial role in NSCLC (2). PMA increased PAEP/glycodelin expression in the H1975 cells, whereas in the 2106T cells, all of the inducers caused higher relative protein levels. Herein, the 


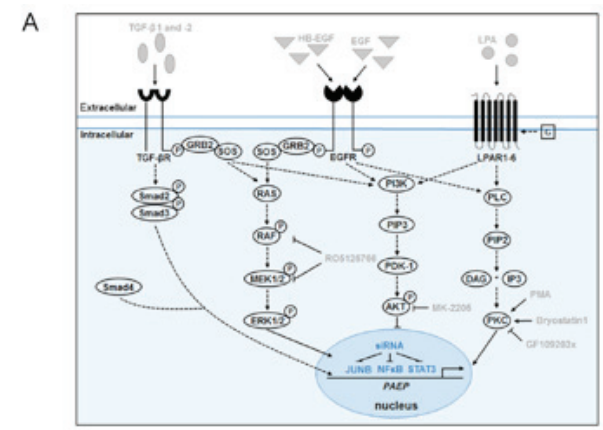

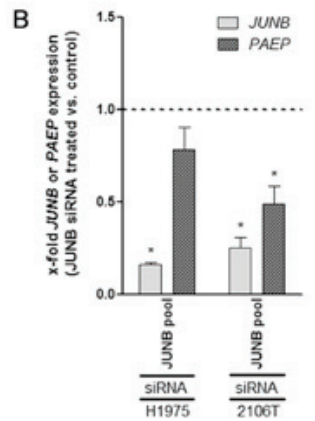

C

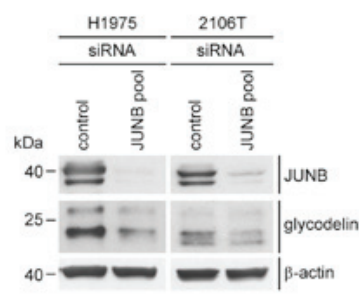

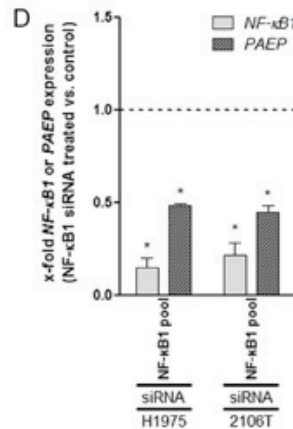

E

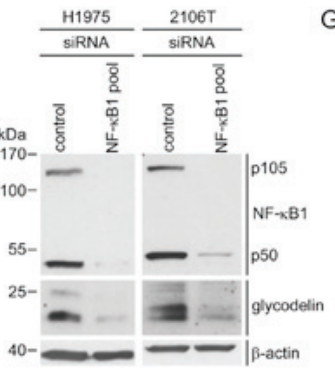

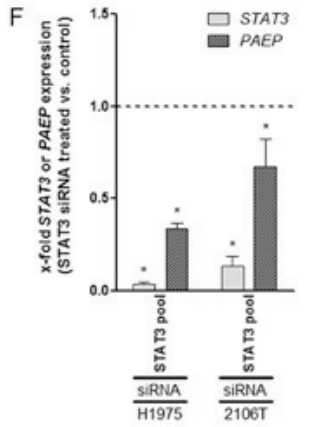

G

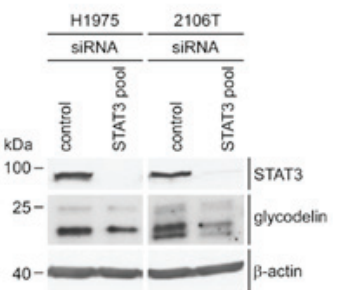

Figure 3. PAEP/glycodelin amounts in NSCLC cells are influenced by the transcription factors JUNB, NF- $\kappa$ B1 and STAT3. (A) Overview of previously applied pathway inducers as well as signalling pathway modulators (grey) and transcription factors, which were investigated in the next experiments (blue). Dotted arrows illustrate activation of pathway components known from the literature $(2,27,28,38,43,44,58)$, whereas drawn down lines show directly proven influences. (B-G) H1975 and 2106T cells were transfected with a pool of 3 to 4 different siRNAs targeting JUNB, NF- $\kappa B 1$ and STAT3 for $72 \mathrm{~h}$. (B, D and F) qPCR analyses determined the expression of the particular siRNA targeted gene (light grey) and PAEP (dark grey), which were investigated in 3 independent experiments. Dotted line at 1 represents the expression in control-treated cells (mean of the $\mathrm{C}_{\mathrm{t}}$-values and mean $\mathrm{SD}$ are shown). Statistical significance was defined as ${ }^{*} \mathrm{P}<0.05$ (unpaired t-test; referring to control-treated cells). (C, E and G) Protein expression of JUNB, NF- $\mathrm{kB} 1, \mathrm{STAT} 3$, after the silencing of their corresponding genes, and glycodelin was examined by western blot analysis. $\beta$-actin was used as a loading control (cropped blots are shown). PAEP, progesterone associated endometrial protein; NSCLC, non-small cell lung cancer.

most prominent effect was demonstrated by PMA treatment (Fig. 1A and B).

Additional pregnancy-associated hormones (relaxin1 and 2, progesterone, and hCG), as well as other hormones [endothelin-1, prostaglandins (PGE1, PGE2, PGI2, PGF2)], which were upregulated after $P A E P$ silencing in the NSCLC cell lines in our previous study, were analysed with regard to their influence on $P A E P /$ glycodelin expression (20). Exclusively, hCG modulated $P A E P /$ glycodelin expression in the H1975 and 2106T cells (data not shown). However, only high hCG concentrations led to an increased $P A E P /$ glycodelin expression, but also to a degradation of $\beta$-actin. None of the other hormones influenced glycodelin levels at the RNA or protein level in the investigated NSCLC cell lines (data not shown). Due to these results, the tested hormones were excluded from subsequent analyses.

The inducers that elevated $P A E P /$ glycodelin expression (Fig. 1A, black arrows) were applied in subsequent microarray analyses to gain insight for further pathway inducers or downstream pathways influencing glycodelin expression.
Therefore, an upstream regulator analysis [software: IPA] of differentially expressed genes $(<-1.5$ or $>1.5)$ was performed (Fig. 1C). As observed before, PMA, EGFR and LPA were confirmed as upstream regulators. Moreover, several other possibly involved upstream regulators appeared. For the following experiments, TGF- $\beta 1, \mathrm{NF}-\kappa \mathrm{B}$ complex, $\mathrm{NF}-\kappa \mathrm{B} 1$, PRKCD (isoform of PKC), rapidly accelerated fibrosarcoma (RAF)1,ERK1/2, MEK and JUN were selected, since they were determined to be involved in signalling pathways associated with the regulation of glycodelin expression (Fig. 1C) (38-40) or they were previously directly shown to influence glycodelin amounts (29).

Since TGF- $\beta$ is a further possible pathway inducer, its effect on $P A E P /$ glycodelin expression was consecutively investigated. Other downstream signalling pathway components and transcription factors were addressed in subsequent experiments. TGF- $\beta 1,-2$ and -3 led to elevated RNA and protein levels in the 2106T, but not in the H1975 cells (Fig. 1D and E). Subsequent experiments focused on TGF- $\beta 1$ and -2 , since these two isoforms exhibited the most potent effect. 
A

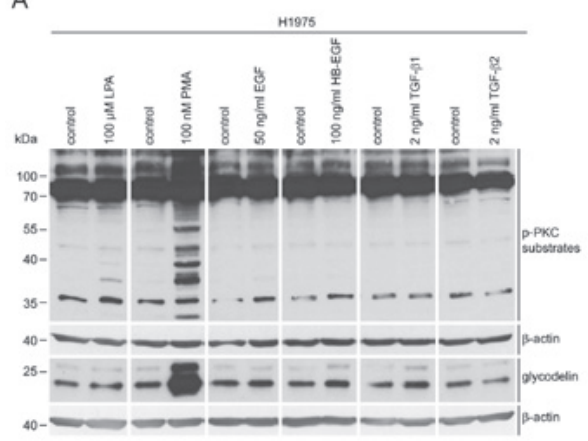

B

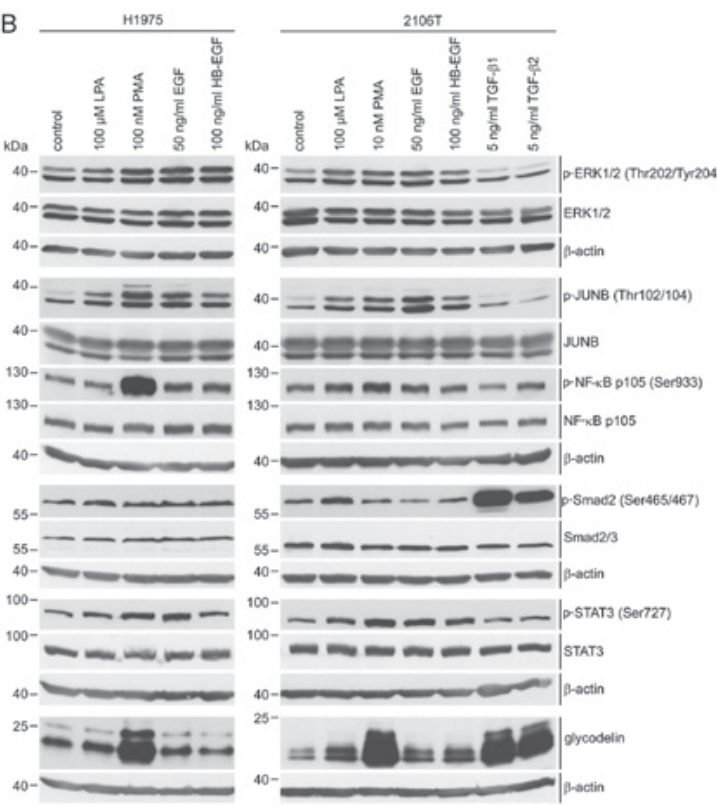

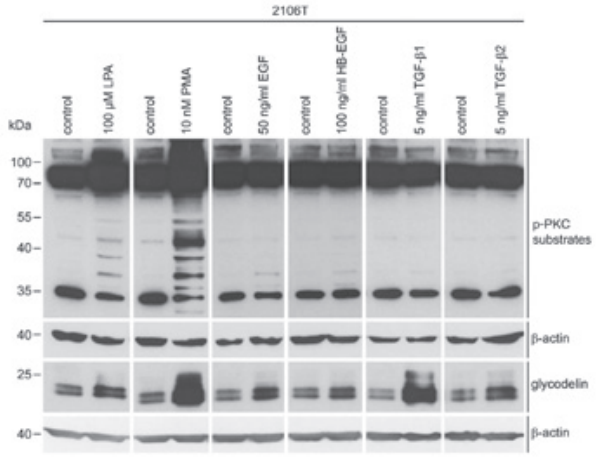

C

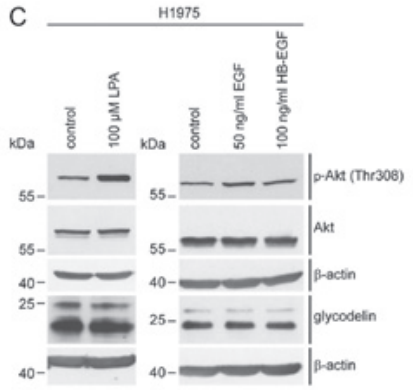

Figure 4. Effects of pathway inducers on signalling pathways, transcription factors and glycodelin expression in NSCLC cells. (A-C) H1975 and 2106T cells were serum-starved overnight. The cells were treated with the indicated pathway inducers for 30-60 min to detect substrates phosphorylated by PKC, ERK phosphorylation (Thr202/Tyr204), JUNB phosphorylation (Thr102/104), NF-кB p105 phosphorylation (Ser933), Smad2 phosphorylation (Ser465/467), STAT3 phosphorylation (Ser727) and AKT phosphorylation. The detection of glycodelin followed $24 \mathrm{~h}$ following treatment. Corresponding non-phosphorylated proteins and $\beta$-actin served as controls (cropped blots). PKC, protein kinase C.

Downstream signalling pathways involving $P K C, A K T$ and $R A F / M E K$ are mediators in the regulation of PAEP/glycodelin expression. There are distinct downstream signalling pathways that can be activated by the former tested inducers. Therefore, we investigated the influence of the PKC, PI3K/AKT and MEK/ERK signalling cascade on $P A E P /$ glycodelin expression by applying different pathway modulators (Fig. 2A). Activating PKC with bryostatin1 led to an increased glycodelin expression at the RNA and protein level in both cell lines (Fig. 2B and C). The PKC inhibitor GF109203X had a slight inducing or no effect at low concentrations (1 and $5 \mu \mathrm{M}$ ), but markedly decreased the $P A E P /$ glycodelin amounts at the highest concentration $(10 \mu \mathrm{M})$ (Fig. 2D and E). The inhibition of AKT with MK-2206 (41) led to an increase in PAEP/glycodelin expression in the H1975, but not in the 2106T cells (Fig. 2F and G). The $P A E P /$ glycodelin levels were negatively affected by the RAF/MEK inhibitor, RO5126766 (42), in both cell lines (Fig. 2H and I).

The levels of PAEP/glycodelin are regulated by the transcription factors, JUNB, NF- $\kappa B 1$ and STAT3. Using bioinformatics analysis of the promotor region of PAEP, we identified a set of transcription factors that might bind before or within this region and can be activated by at least one of the signalling pathways tested before. For these reasons and based on the results of the microarray gene expression profiling (Fig. 1C), we focused on the involvement of the jun-B proto-oncogene (JUNB), NF-кB1 and STAT3 in PAEP/glycodelin expression. The expression of the transcription factors was silenced by the siRNA transfection of the H1975 and 2106T cells (Fig. 3A). All of the individual siRNAs and the pooled siRNAs decreased the expression of the specific genes and proteins (Fig. 3B-G). In the case of NF- $\kappa \mathrm{B} 1$, its precursor (p105), as well as its active form (p50) were decreased. The knockdown of the 3 genes led to a decreased PAEP expression in both cell lines (Fig. 3B-F). Western blot analysis confirmed the RNA data at the protein level (Fig. 3C, E and G). Thus, JUNB, NF- $\kappa B 1$ and STAT3 silencing diminished the glycodelin amounts in the H1975 and 2106T cells.

Associations between pathway inducers, downstream pathways and transcription factors as regards their effect on glycodelin expression. We further aimed to better understand the crosstalk between the investigated pathway inducers, signalling pathways and transcription factors. The H1975 and 


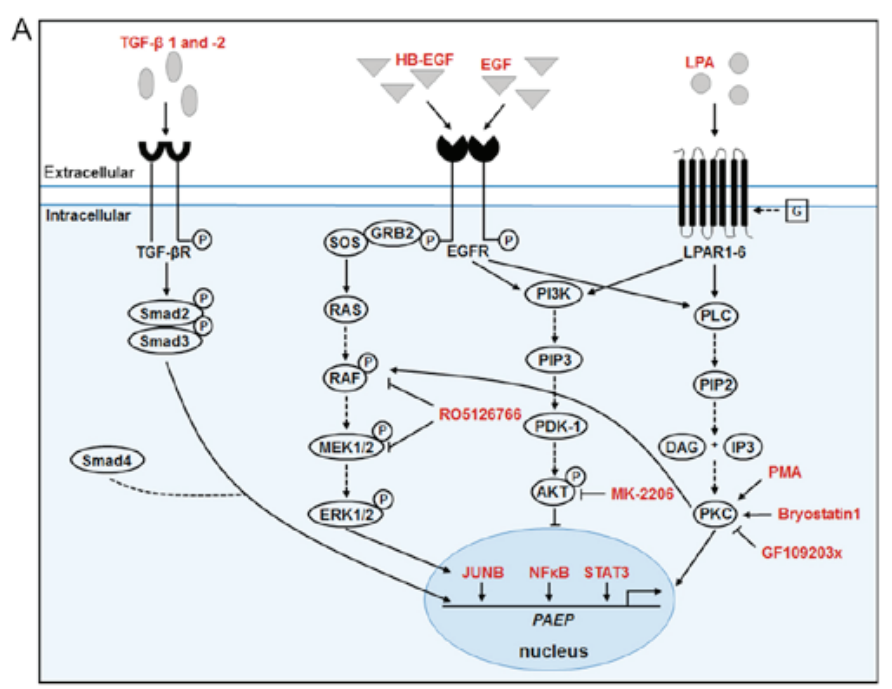

\begin{tabular}{lcc} 
B & Adenocacinoma & $\begin{array}{c}\text { Squamous cell } \\
\text { carcinoma }\end{array}$ \\
\hline Upstream regulators & 6.08 & 5.82 \\
TGF- $\beta 1$ & 1.49 & 2.36 \\
TGF- $\beta 2$ & 2.50 & 3.86 \\
TGF- 33 & 1.45 & 3.10 \\
SMAD2 & 1.78 & 2.72 \\
HBEGF & 3.34 & 5.17 \\
EGF & N/A & 1.00 \\
LPA & 2.14 & 6.58 \\
PMA & 1.86 & 5.59 \\
RAF1 & 1.84 & 2.14 \\
Mek & 0.98 & 2.67 \\
Akt & 1.79 & 2.46 \\
PKC(s) & 2.31 & 3.20 \\
JUNB & 3.50 & 3.35 \\
STAT3 & 2.79 & 3.41 \\
NF-KB1 & &
\end{tabular}

Figure 5. Summary and upstream regulators in NSCLC tumours with high PAEP expression. (A) Summary of all investigated candidates (red), showing their influence on $P A E P / g l y c o d e l i n$ expression. Examined effects are depicted with drawn down lines and stimulations known from literature are shown with dotted arrows. (B) In a microarray analysis, the gene expression in tumour tissue of lung adenocarcinomas (20 each) and of lung squamous cell carcinomas (15 each) with high PAEP expression was compared with the same numbers of tumour tissues with low PAEP expression. These data were further analysed performing an upstream regulator analysis with the software IPA. Only upstream regulators also analysed in the cell lines were depicted. Shown are the activation z-scores (significant for $>2$ or <-2). PAEP, progesterone associated endometrial protein; NSCLC, non-small cell lung cancer.

2106T cells were treated with the pathway inducers, LPA, PMA, EGF, HB-EGF, TGF- $\beta 1$ and -2 . Subsequently, the activity of downstream pathways and transcription factors was examined by western blot analysis. To detect the stimulation of signalling pathways, the phosphorylation of only one representative component was examined. In order to determine the best point of time suitable for detecting the induction of phosphorylation, we exemplarily examined substrates phosphorylated by conventional PKCs at different time periods following treatment with PMA. The strongest phosphorylation of PKC substrates was observed between $30 \mathrm{~min}$ and $1 \mathrm{~h}$ following induction (data not shown). Consequently, these treatment durations were applied in further analysis.

PMA was the only pathway inducer that elevated the expression of glycodelin in the H1975 cells. By contrast, the glycodelin levels were increased due to each of the investigated inducers in the 2106T cells (Fig. 4A and B). LPA and PMA activated PKC in the $\mathrm{H} 1975$ cells, while the other pathway inducers exhibited no effect on PKC activity. In the 2106T cells, PKC was activated by LPA, PMA and to a lower extent also by EGF and HB-EGF treatment. TGF- $\beta 1$ and -2 did not influence PKC activity (Fig. 4A).

Fig. 4B provides an overview of the activation patterns of the investigated signalling molecules. Treatment with LPA, PMA, EGF and HB-EGF resulted in an increased phosphorylation of ERK, JUNB and slightly also of STAT3 in the H1975 and $2106 \mathrm{~T}$ cells. NF- $\kappa \mathrm{B}$ p105 was mainly activated by PMA in both cell lines. This indicated that LPA, EGF and HB-EGF stimulated glycodelin expression inducing pathways in the H1975 cells without having an effect on glycodelin levels. As demonstrated above, the inhibition of AKT led to an increase in glycodelin expression in the H1975 cells (Fig. 2F and G). Therefore, we investigated the influence of LPA, EGF and HB-EGF on AKT activation. This kinase was strongly phosphorylated following treatment with LPA, whereas EGF and HB-EGF caused only a weak AKT phosphorylation (Fig. 4C).
Stimulation with TGF- $\beta 1$ and -2 resulted in a marked activation of Smad 2 in the 2106T cells, followed by an upregulation of glycodelin in the 2106T (Fig. 4B), but not in the H1975 cells (Fig. 1D and E).

Candidates regulating PAEP/glycodelin expression in cell lines are also activated in NSCLC tissues with a high PAEP expression. The overview shown in Fig. 5A shows the complex regulatory mechanism of glycodelin expression in NSCLC cells suggested by the results of this study. While in the lung SQCC cell line TGF- $\beta$ seemed to be a major inducer of $P A E P /$ glycodelin expression, the regulation in the tested lung ADC cell line was strongly influenced by AKT. PKC played a major role in the stimulation of $P A E P /$ glycodelin expression in both cell lines. To validate the observed influences on $P A E P / g l y c o d e l i n$ expression in NSCLC patients, we performed an analysis using the qPCR-derived patient data of our recent study (20). Patients with the highest or the lowest PAEP expression in ADC (20 each) and SQCC (15 each) were selected (Table I) and microarray gene expression profiling was performed (Fig. 5B). For further analysis of differentially expressed genes $(<-1.5$ or $>1.5)$, the software IPA was used to identify upstream regulators. Of note, most of the candidates that led to an elevated expression of $\mathrm{PAEP} / \mathrm{glycodelin}$ in the cell lines were also identified as upstream regulators in NSCLC tissues with a high PAEP expression. According to the in vitro results, the upstream regulators were more active in SQCC than in ADC. Only the activity of TGF- $\beta 1$ and STAT3 was similar in both NSCLC subtypes (Fig. 5B).

\section{Discussion}

Elucidating the regulation of $P A E P /$ glycodelin expression could provide insight for the usage of glycodelin as a therapeutic target to weaken the immune system defence of NSCLC tumours. After previously demonstrating the cellular 
Table I. Patient and tumour characteristics.

\begin{tabular}{|c|c|}
\hline Parameter & Total $(n=70)$ \\
\hline \multicolumn{2}{|l|}{ Age, years } \\
\hline Median (range) & $65(40-83)$ \\
\hline \multicolumn{2}{|l|}{ Sex } \\
\hline Male & 51 \\
\hline Female & 19 \\
\hline \multicolumn{2}{|l|}{ Histology } \\
\hline Adenocarcinoma & 40 \\
\hline Squamous cell carcinoma & 30 \\
\hline \multicolumn{2}{|l|}{ Smoking status } \\
\hline Smoker & 23 \\
\hline Non-smoker $<6$ months & 15 \\
\hline Non-smoker $>6$ months & 28 \\
\hline Never-smoker & 4 \\
\hline \multicolumn{2}{|l|}{ Therapy } \\
\hline $\mathrm{OP}$ & 40 \\
\hline $\mathrm{OP} / \mathrm{RT}$ & 2 \\
\hline $\mathrm{OP} / \mathrm{CT}$ & 24 \\
\hline OP/RT/CT & 4 \\
\hline \multicolumn{2}{|l|}{ P stage } \\
\hline IA & 8 \\
\hline IB & 31 \\
\hline IIA & 0 \\
\hline IIB & 17 \\
\hline IIIA & 14 \\
\hline \multicolumn{2}{|l|}{$\mathrm{ECO}$} \\
\hline 0 & 65 \\
\hline 1 & 4 \\
\hline 2 & 1 \\
\hline
\end{tabular}

OP, surgery; RT, radiotherapy; CT, chemotherapy; P stage, pathological stage; ECOG, Eastern Cooperative Oncology Group.

functions of glycodelin (20), in this study, we analysed the thus far unknown underlying mechanisms regulating the expression of $P A E P /$ glycodelin in NSCLC cell lines and NSCLC tissues. At least to the best of our knowledge, for the first time, we identified involved pathway inducers, intracellular signalling pathways and transcription factors in this tumour type. In this context, a complex crosstalk of various signalling pathways (Fig. 5A) and some differences between the ADC cell line H1975 and the SQCC cell line 2106T were observed.

In contrast to many NSCLC tumours, only few lung carcinoma cell lines, such as H1975 and 2106T, were identified to express glycodelin (20). Several studies have already shown the inhibitory effects of glycodelin on the apoptosis, proliferation and the activity of immune cells (reviewed in 24). Together with the assumption that NSCLC tumours secrete glycodelin to circumvent immunosurveillance, this suggests a major role of the tumour microenvironment. Lacking this environment in vitro, the majority of the NSCLC cell lines might stop $P A E P / g l y c o d e l i n$ expression. Gottschling et al observed similarities and various differences in the gene expression patterns of two SQCC cell lines and their corresponding tissue. In particular, gene clusters associated with immune response, adhesion, proliferation, differentiation and angiogenesis were strongly silenced in the cell lines and therefore differed from their particular tissue. They also assumed the microenvironment as a reason for this observation (36).

In the H1975 cells, PMA was the only pathway inducer that stimulated glycodelin expression. By contrast, this effect was observed after LPA, PMA, EGF, HB-EGF, TGF- $\beta 1,-2$ and -3 treatment in the 2106T cells. LPA and PMA have already been postulated to increase $P A E P /$ glycodelin expression in different cell lines $(25,26)$. As regards EGF, HB-EGF and TGF- $\beta$, there are no published data available describing an influence of these inducers on $P A E P /$ glycodelin expression, at least to the best of our knowledge. In this study, we demonstrated that all of the inducers activated the PKC and/or the MEK/ERK pathway downstream, with the exception of TGF- $\beta$. In accordance with our findings, a previous study also postulated an association of MEK and the expression of glycodelin in other cells (29). The inhibition of both pathways led to a decreased $P A E P /$ glycodelin expression in the NSCLC cell lines. Therefore, we hypothesised that stimulating these pathways with the different pathway

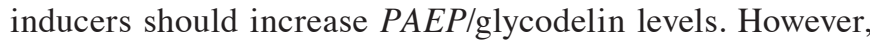
this hypothesis could be completely confirmed only in the $2106 \mathrm{~T}$ cells, whereas the $P A E P /$ glycodelin levels were altered exclusively after PMA treatment in the H1975 cells. The discrepancy may be explained by an LPA-, EGF- and HB-EGF-mediated activation of the PI3K/AKT pathway, which was shown to suppress $P A E P /$ glycodelin expression in the H1975 cells. This suggests an antagonizing effect to the PKC- and MEK/ERK pathway-dependent stimulation of $\mathrm{PAEP} / \mathrm{glycodelin}$ expression. In this regard, former literature data have demonstrated a LPA-, EGF- and HB-EGF-dependent PI3K/AKT pathway stimulation $(43,44)$. Contrary to the results observed with the $\mathrm{H} 1975$ cells, treatment of the 2106T cells with an AKT inhibitor did not affect PAEP/glycodelin expression. Currently, the reason for these distinct results is unclear; however, activating EGFR (T790M, L858R) and PIK3CA (G118D) mutations in H1975 cells may play a role. Each of these three mutations has been previously shown to be associated with the activation of AKT (45-49). This suggests a generally stronger AKT activity accompanied by a lower glycodelin expression in H1975 cells.

Depending on the particular cell line, treatment with LPA, PMA, EGF and HB-EGF did not only activate the PKC and MEK/ERK pathway, but also the transcription factors, JUNB and STAT3. Therefore, it could be hypothesised that both transcription factors are involved in these signalling cascades, as already described in previous studies (39,50-52). NF- $\kappa \mathrm{B} 1$, which has been shown to be associated with both the PKC and MEK/ERK pathways in the literature $(40,53)$, was mainly affected by the PMA-stimulated PKC signalling cascade in our analyses. TGF- $\beta 1$ and -2 , as well as LPA induced the phosphorylation of Smad2 in the 2106T cells, which is also in concordance with previous literature data $(54,55)$. As none of the examined other pathways or transcription factors was affected by TGF- $\beta$, it can be concluded that glycodelin expression is solely influenced by the canonical TGF- $\beta$ pathway. 
The in vitro derived data were confirmed in NSCLC patient tissues to a great extent. Most of the analysed $P A E P / g l y c o d e l i n$ expression-regulating candidates in the cell lines were also found as upstream regulators in the patient tissues. In accordance with the cell line-derived data, a stronger activation of the upstream regulators was determined in SQCC compared to ADC, apart from TGF- $\beta 1$ and STAT3. Analogous to the results observed with the cell lines, we expected a decreased AKT activity in ADC tumours with a high PAEP expression. However, the activation of AKT was slightly increased in these tumour tissues. As already mentioned, we assume that only an activated PI3K/AKT pathway, as it was shown for the mutations T790M (EGFR), L858R (EGFR) and G118D (PIK3CA) (45-49) of H1975 cells, influences $P A E P / g l y c o d e l i n$ expression. The mutational status of the patients is not known, as molecular alterations are not tested in operated patients. Probably, an activated PI3K/AKT pathway occurs only in a few patients. In a previous study activated PI3K/AKT pathways were shown in $25 \%$ of the analysed lung ADCs (56). This might be the reason for the differences between the in vitro and the in vivo data.

The pathways that were shown to play a role in the regulation of $P A E P /$ glycodelin expression are known to be altered in cancer. Actually, drugs for the treatment of NSCLC patients are available targeting the MEK/ERK pathway, which stimulates the $P A E P /$ glycodelin expression. Since 2017, a combined therapy of a BRAF inhibitor (Dabrafenib) and MEK inhibitor (Trametinib) is approved for NSCLC patients with a BRAF-V600 mutation. Our results provide evidence that this BRAF/MEK inhibitor treatment may possibly downregulate glycodelin expression in tumour cells and hence decrease the postulated immunosuppressive effect. AKT inhibitors are currently in clinical development for cancer therapy (57). According to our results, the treatment of patients with mutational activated AKT might increase the expression of glycodelin and therefore could promote immunosurveillance mediated by cancer cells.

As the tumour microenvironment is assumed to play a major role in the regulation of $P A E P /$ glycodelin expression, future experiments should aim to address this association. Therefore, we aim to perform co-culture experiments of NSCLC lines with fibroblasts and immune cells in order to analyse the effect on $P A E P / g l y c o d e l i n$ expression. Our group has already postulated an upregulation of immune system regulating ligands, such as programmed cell death 1 ligand 1 (PD-L1), in PAEP knockdown NSCLC cell lines (20). Therefore, further investigations are required to reason glycodelin as a target of NSCLC treatments.

In conclusion, in this study, for the first time (at least to the best of our knowledge), we elucidated regulators of $P A E P /$ glycodelin expression in NSCLC. Our data point towards a putative model, in which glycodelin expression is stimulated by the canonical TGF- $\beta$ pathway in SQCC cells and the PKC signalling cascade in both NSCLC cell lines. The PI3K/AKT pathway inhibits glycodelin expression in ADC cells and an antagonizing role towards the other investigated signalling cascades is suggested herein. TGF- $\beta$, the PI3K/AKT signalling cascade, as well as the MEK/ERK pathway, the latter stimulated glycodelin expression, are targets of NSCLC drugs that are already approved or currently under investigations. Our results provide evidence that inhibiting these targets affects the expression of glycodelin and therefore, exerts an immunosuppressive effect on NSCLC tumours. Furthermore, understanding the regulation of glycodelin expression may lead to the development of novel therapeutic approaches to weaken the immune system defence of NSCLC tumours.

\section{Acknowledgements}

The authors would like to thank Ms. Elizabeth Chang Xu, Mr. Martin Fallenbuechel, Ms. Carmen Hoppstock, Ms. Christa Stolp and Ms. Andrea Bopp for their expert technical assistance. Furthermore, the authors wish to thank Dr. Dmytro Dvornikov (Systems Biology of Signal Transduction, DKFZ), who kindly provided the pSmad2 and Smad $2 / 3$ antibodies. The tissue samples were provided by the Lung Biobank Heidelberg, a member of the accredited Tissue Bank of the National Centre for Tumour Diseases (NCT) Heidelberg, the BioMaterialBank Heidelberg and the German Centre for Lung Research (DZL) in accordance with the regulations of the tissue bank and the approval of the ethics committee of the University of Heidelberg.

\section{Funding}

This study was financially supported in part by the Federal Ministry of Education and Research (BMBF, Germany) and the German Centre for Lung Research (DZL, Germany).

\section{Availability of data and materials}

The microarray datasets generated and analysed during the current study are available in the NCBI GEO database (GSE115458; https://www.ncbi.nlm.nih.gov/geo/query/acc. cgi?acc=GSE115458).

\section{Authors' contributions}

RW was involved in manuscript writing and the performance of the experiments. RW, MM, TM, HS and MAS were involved in the conception and design of the study. RW, MM, TM, MT, AW, HW, FJFH and MAS were involved in the acquisition of material and data. RW, MM, TM, MT, HS, AW, HW, FJFH and MAS were involved in data analysis and interpretation. All authors have read and approved the manuscript.

\section{Ethics approval and consent to participate}

The study was approved by the local Ethics Committee of the University of Heidelberg (no. 270/2001).

\section{Patient consent for publication}

Not applicable.

\section{Competing interests}

The authors declare no competing interests. 


\section{References}

1. Ferlay J, Soerjomataram I, Dikshit R, Eser S, Mathers C, Rebelo M, Parkin DM, Forman D and Bray F: Cancer incidence and mortality worldwide: Sources, methods and major patterns in GLOBOCAN 2012. Int J Cancer 136: E359-E386, 2015.

2. da Cunha Santos G, Shepherd FA and Tsao MS: EGFR mutations and lung cancer. Annu Rev Pathol 6: 49-69, 2011.

3. Morris HR, Dell A, Easton RL, Panico M, Koistinen H, Koistinen R, Oehninger S, Patankar MS, Seppala M and Clark GF: Gender-specific glycosylation of human glycodelin affects its contraceptive activity. J Biol Chem 271: 32159-32167, 1996.

4. Dell A, Morris HR, Easton RL,Panico M,Patankar M,OehnigerS, Koistinen R, Koistinen H, Seppala M and Clark GF: Structural analysis of the oligosaccharides derived from glycodelin, a human glycoprotein with potent immunosuppressive and contraceptive activities. J Biol Chem 270: 24116-24126, 1995.

5. Chiu PC, Chung MK, Koistinen R, Koistinen H, Seppala M, Ho PC, Ng EH, Lee KF and Yeung WS: Cumulus oophorus-associated glycodelin-C displaces sperm-bound glycodelin-A and -F and stimulates spermatozoa-zona pellucida binding. J Biol Chem 282: 5378-5388, 2007.

6. Seppälä M, Koistinen H, Koistinen R, Chiu PC and Yeung WS: Glycosylation related actions of glycodelin: Gamete, cumulus cell, immune cell and clinical associations. Hum Reprod Update 13: 275-287, 2007.

7. Okamoto N, Uchida A, Takakura K, Kariya Y, Kanzaki H, Riittinen L, Koistinen R, Seppälä M and Mori T: Suppression by human placental protein 14 of natural killer cell activity. Am J Reprod Immunol 26: 137-142, 1991

8. Laird SM, Hill CJ, Warren MA, Tuckerman EM and Li TC: The production of placental protein 14 by human uterine tubal epithelial cells in culture. Hum Reprod 10: 1346-1351, 1995.

9. Fazleabas AT, Donnelly KM, Srinivasan S, Fortman JD and Miller JB: Modulation of the baboon (Papio anubis) uterine endometrium by chorionic gonadotrophin during the period of uterine receptivity. Proc Natl Acad Sci USA 96: 2543-2548, 1999.

10. Toth B, Roth K, Kunert-Keil C, Scholz C, Schulze S, Mylonas I, Friese $\mathrm{K}$ and Jeschke U: Glycodelin protein and mRNA is downregulated in human first trimester abortion and partially upregulated in mole pregnancy. J Histochem Cytochem 56 : 477-485, 2008.

11. Tseng L, Zhu HH, Mazella J, Koistinen H and Seppälä M: Relaxin stimulates glycodelin mRNA and protein concentrations in human endometrial glandular epithelial cells. Mol Hum Reprod 5: 372-375, 1999.

12. Kämäräinen M, Halttunen M, Koistinen R, von Boguslawsky K, von Smitten K, Andersson LC and Seppälä M: Expression of glycodelin in human breast and breast cancer. Int J Cancer 83: 738-742, 1999.

13. Hackenberg R, Loos S, Nia AH, Kunzmann R and Schulz KD: Expression of placental protein 14 by the new endometrial cancer cell line MFE-280 in vitro and by endometrial carcinomas in vivo. Anticancer Res 18 (2A): 1153-1158, 1998.

14. Kämäräinen M, Leivo I, Koistinen R, Julkunen M, Karvonen U, Rutanen EM and Seppälä M: Normal human ovary and ovarian tumors express glycodelin, a glycoprotein with immunosuppressive and contraceptive properties. Am J Pathol 148: $1435-1443,1996$.

15. Connor JP, Brudney A, Ferrer K and Fazleabas AT: Glycodelin-A expression in the uterine cervix. Gynecol Oncol 79: 216-219, 2000

16. Kämäräinen M, Miettinen M, Seppala M, von Boguslawsky K, Benassi MS, Böhling T and Andersson LC: Epithelial expression of glycodelin in biphasic synovial sarcomas. Int J Cancer 76 : 487-490, 1998

17. Ren S, Liu S, Howell PM Jr, Zhang G, Pannell L, Samant R Shevde-Samant L, Tucker JA, Fodstad O and Riker AI: Functional characterization of the progestagen-associated endometria protein gene in human melanoma. J Cell Mol Med 14 (6B): 1432-1442, 2010.

18. Schneider MA, Muley T, Kahn NC, Warth A, Thomas M, Herth FJ, Dienemann H and Meister M: Glycodelin is a potential novel follow-up biomarker for malignant pleural mesothelioma. Oncotarget 7: 71285-71297, 2016.

19. Kunert-Keil C, Steinmüller F, Jeschke U, Gredes T and Gedrange T: Immunolocalization of glycodelin in human adenocarcinoma of the lung, squamous cell carcinoma of the lung and lung metastases of colonic adenocarcinoma. Acta Histochem 113: 798-802, 2011
20. Schneider MA, Granzow M, Warth A, Schnabel PA, Thomas M, Herth FJ, Dienemann H, Muley T and Meister M: Glycodelin: A New Biomarker with Immunomodulatory Functions in Non-Small Cell Lung Cancer. Clin Cancer Res 21: 3529-3540, 2015.

21. Lenhard M, Heublein S, Kunert-Keil C, Vrekoussis T, Lomba I, Ditsch N, Mayr D, Friese K and Jeschke U: Immunosuppressive Glycodelin A is an independent marker for poor prognosis in endometrial cancer. BMC Cancer 13: 616, 2013.

22. Scholz C, Heublein S, Lenhard M, Friese K, Mayr D and Jeschke U: Glycodelin A is a prognostic marker to predict poor outcome in advanced stage ovarian cancer patients. BMC Res Notes 5: 551, 2012.

23. Mandelin E, Lassus H, Seppälä M, Leminen A, Gustafsson JA, Cheng G, Bützow R and Koistinen R: Glycodelin in ovarian serous carcinoma: Association with differentiation and survival. Cancer Res 63: 6258-6264, 2003.

24. Cui J, Liu Y and Wang X: The Roles of Glycodelin in Cancer Development and Progression. Front Immunol 8: 1685, 2017.

25. Morrow DM, Xiong N, Getty RR, Ratajczak MZ, Morgan D, Seppala M, Riittinen L, Gewirtz AM and Tykocinski ML: Hematopoietic placental protein 14. An immunosuppressive factor in cells of the megakaryocytic lineage. Am J Pathol 145: 1485-1495, 1994

26. Ramachandran S, Ramaswamy S, Cho Ch and Parthasarathy S: Lysophosphatidic acid induces glycodelin gene expression in cancer cells. Cancer Lett 177: 197-202, 2002.

27. Bazzi MD and Nelsestuen GL: Differences in the effects of phorbol esters and diacylglycerols on protein kinase $\mathrm{C}$. Biochemistry 28: 9317-9323, 1989.

28. Sando JJ and Chertihin OI: Activation of protein kinase $\mathrm{C}$ by lysophosphatidic acid: Dependence on composition of phospholipid vesicles. Biochem J 317: 583-588, 1996.

29. Xu JW, Yasui N, Ikeda K, Pan WJ, Watanabe J, Shiotani M, Yanaihara A, Miki T and Yamori Y: Isoflavones regulate secretion of leukemia inhibitory factor and transforming growth factor $\{$ beta\} and expression of glycodelin in human endometrial epithelial cells. J Endocrinol 196: 425-433, 2008.

30. Dydensborg AB, Rose AA, Wilson BJ, Grote D, Paquet M, Giguère V, Siegel PM and Bouchard M: GATA3 inhibits breast cancer growth and pulmonary breast cancer metastasis. Oncogene 28: 2634-2642, 2009.

31. Ren S, Howell PM Jr, Han Y, Wang J, Liu M, Wang Y, Quan G, Du W, Fang L and Riker AI: Overexpression of the progestagen-associated endometrial protein gene is associated with microphthalmia-associated transcription factor in human melanoma. Ochsner J 11: 212-219, 2011.

32. Gao J, Mazella J, Seppala M and Tseng L: Ligand activated hPR modulates the glycodelin promoter activity through the Spl sites in human endometrial adenocarcinoma cells. Mol Cell Endocrinol 176: 97-102, 2001.

33. Tabbaa ZM, Zheng Y and Daftary GS: KLF11 epigenetically regulates glycodelin-A, a marker of endometrial biology via histone-modifying chromatin mechanisms. Reprod Sci 21: 319-328, 2014.

34. Beasley MB, Brambilla E and Travis WD: The 2004 World Health Organization classification of lung tumors. Semin Roentgenol 40: 90-97, 2005.

35. Wittekind C: 2010 TNM system: On the 7th edition of TNM classification of malignant tumors. Pathologe 31: 331-332, 2010 (In German)

36. Gottschling S, Jauch A, Kuner R, Herpel E, Mueller-Decker K, Schnabel PA, Xu EC, Muley T, Sültmann H, Bender C, et al: Establishment and comparative characterization of novel squamous cell non-small cell lung cancer cell lines and their corresponding tumor tissue. Lung Cancer 75: 45-57, 2012.

37. Bustin SA, Benes V, Garson JA, Hellemans J, Huggett J, Kubista M, Mueller R, Nolan T, Pfaffl MW, Shipley GL, et al: The MIQE guidelines: Minimum information for publication of quantitative real-time PCR experiments. Clin Chem 55: 611-622, 2009.

38. Zhang YE: Non-Smad pathways in TGF-beta signaling. Cell Res 19: 128-139, 2009.

39. Hodge C, Liao J, Stofega M, Guan K, Carter-Su C and Schwartz J: Growth hormone stimulates phosphorylation and activation of elk-1 and expression of c-fos, egr-1, and junB through activation of extracellular signal-regulated kinases 1 and 2 . J Biol Chem 273: 31327-31336, 1998.

40. Dhawan P and Richmond A: A novel NF-kappa B-inducing kinase-MAPK signaling pathway up-regulates NF-kappa B activity in melanoma cells. J Biol Chem 277: 7920-7928, 2002. 
41. Holland WS, Chinn DC, Lara PN Jr, Gandara DR and Mack PC: Effects of AKT inhibition on HGF-mediated erlotinib resistance in non-small cell lung cancer cell lines. J Cancer Res Clin Oncol 141: 615-626, 2015.

42. Wada M, Horinaka M, Yamazaki T, Katoh N and Sakai T: The dual RAF/MEK inhibitor CH5126766/RO5126766 may be a potential therapy for RAS-mutated tumor cells. PLoS One 9: e113217, 2014

43. Jorissen RN, Walker F, Pouliot N, Garrett TP, Ward CW and Burgess AW: Epidermal growth factor receptor: Mechanisms of activation and signalling. Exp Cell Res 284: 31-53, 2003.

44. Riaz A, Huang Y and Johansson S: G-Protein-Coupled Lysophosphatidic Acid Receptors and Their Regulation of AKT Signaling. Int J Mol Sci 17: 215, 2016.

45. Wee P and Wang Z: Epidermal Growth Factor Receptor Cell Proliferation Signaling Pathways. Cancers (Basel) 9: 9, 2017.

46. Sordella R, Bell DW, Haber DA and Settleman J: Gefitinib-sensitizing EGFR mutations in lung cancer activate anti-apoptotic pathways. Science 305: 1163-1167, 2004.

47. Tracy S, Mukohara T, Hansen M, Meyerson M, Johnson BE and Jänne PA: Gefitinib induces apoptosis in the EGFRL858R non-small-cell lung cancer cell line H3255. Cancer Res 64: 7241-7244, 2004.

48. Burke JE, Perisic O, Masson GR, Vadas O and Williams RL: Oncogenic mutations mimic and enhance dynamic events in the natural activation of phosphoinositide 3-kinase p110 $\alpha$ (PIK3CA). Proc Natl Acad Sci USA 109: 15259-15264, 2012.

49. Orloff MS, He X, Peterson C, Chen F, Chen JL, Mester JL and Eng C: Germline PIK3CA and AKT1 mutations in Cowden and Cowden-like syndromes. Am J Hum Genet 92: 76-80, 2013.

50. de Groot RP, Auwerx J, Karperien M, Staels B and Kruijer W Activation of junB by PKC and PKA signal transduction through a novel cis-acting element. Nucleic Acids Res 19: 775-781, 1991.
51. Jain N, Zhang T, Kee WH, Li W and Cao X: Protein kinase C delta associates with and phosphorylates Stat 3 in an interleukin-6-dependent manner. J Biol Chem 274: 24392-24400, 1999.

52. Levy DE and Lee CK: What does Stat3 do? J Clin Invest 109: $1143-1148,2002$

53. Ghosh S and Baltimore D: Activation in vitro of NF-kappa B by phosphorylation of its inhibitor I kappa B. Nature 344: 678-682, 1990.

54. Shi Y and Massagué J: Mechanisms of TGF-beta signaling from cell membrane to the nucleus. Cell 113: 685-700, 2003.

55. Jeon ES, Moon HJ, Lee MJ, Song HY, Kim YM, Cho M, Suh DS, Yoon MS, Chang CL, Jung JS, et al: Cancer-derived lysophosphatidic acid stimulates differentiation of human mesenchymal stem cells to myofibroblast-like cells. Stem Cells 26: 789-797, 2008.

56. Collisson EA, Campbell JD, Brooks AN, Berger AH, Lee W, Chmielecki J, Beer DG, Cope L, Creighton CJ, Danilova L, et al; Cancer Genome Atlas Research Network: Comprehensive molecular profiling of lung adenocarcinoma. Nature 511: 543-550, 2014

57. Brown JS and Banerji U: Maximising the potential of AKT inhibitors as anti-cancer treatments. Pharmacol Ther 172: 101-115, 2017.

58. Gazdar AF: Epidermal growth factor receptor inhibition in lung cancer: The evolving role of individualized therapy. Cancer Metastasis Rev 29: 37-48, 2010.

(7) $(2)$ This work is licensed under a Creative Commons Attribution-NonCommercial-NoDerivatives 4.0 International (CC BY-NC-ND 4.0) License. 